\title{
Investigation on cold-formed steel built-up new innovative hat-shaped closed section under bending
}

\author{
P. Manikandan ${ }^{1} \cdot$ A. Ezhilan²
}

Received: 13 December 2018 / Accepted: 19 October 2019 / Published online: 6 November 2019

(c) The Author(s) 2019

\begin{abstract}
The objective of this study is to make the experimental and finite element simulations of buckling behaviour of cold-formed steel (CFS) built-up hat-shaped closed section under simply supported end condition subjected to two-point loading. Numerical simulation is carried out using the software ABAQUS. The test result is compared with numerical results and good correlation is achieved. Next, for validation, a series of parametric studies are carried out using the validated numerical model, such as the effect of length, depth, width, thickness and angle of the inclined element. The local buckling and the interaction of local and flexural buckling are studied. To end with, a design equation is proposed in accordance with the direct strength method specification for CFS structure.
\end{abstract}

Keywords ABAQUS $\cdot$ Hat section $\cdot$ Closed section $\cdot$ Parametric study $\cdot$ Finite element model

\section{Introduction}

In construction industries, two types of cross sections are familiar, one is an open section and another is closed section. On some special situations, it may become necessary to provide an opening through the beam web as an example duct for electricity, air conditioning and so on. The opening/holes in the web significantly affect the strength of the open section, whereas opening is not required in the case of the closed section. Due to the inherent advantages of CFS, nowadays the application of CFS section has increased. Really, the correct analysis and evaluation of the structural responses of the CFS closed section are required for a better and secure design.

Haidarali and Nethercot (2012a, b) have investigated the local-distortional buckling of CFS beam with an edge and intermediate web stiffeners. Manikandan et al. (2012, 2014) and Manikandan and Sukumar (2015, 2016a, b) and his research team has initiated to investigate the behaviour of CFS built-up open and closed beams. This team developed

P. Manikandan

lp_mani@yahoo.com

1 Centre for SONA Structural Engineering Research, Department of Civil Engineering, Sona College of Technology, Salem, Tamil Nadu, India

2 KAR Associates, Krishnagiri, Tamil Nadu, India more innovative CFS beams given the design modification to North American Design (NAS) specification for CFS structure. Likewise, Pan and Yu (2002) have evaluated the bending strength of the hybrid CFS beam. Xu et al. (2009) have tested the flexural strength of CFS built-up box section. Beshara and Lawson (2002), Serrette (2004), Sonu and Singh (2017) also have studied the shear characteristics of rectangular lean duplex stainless steel tubular beam. Alex and Iyappan (2016) carried out experimental and numerical studies on the flexural behaviour of CFS built-up section. Ma et al. (2016) have investigated the behaviour of high-strength CFS tubular beam. From the review of the literature, it is observed that very limited research has been carried out on the behaviour of CFS built-up open and closed sections. However, in the construction industry, the closed section is familiar. Hence, an attempt is made to study the behaviour of CFS built-up hat-shaped section under bending.

\section{Experimental investigation}

Tensile coupon is prepared and tested according to the Indian Specification IS: 1608-2006 (1608-2006). Figure 1 and Table 1 provide the mechanical properties of the tested specimens. The nomenclature and corresponding dimensions of the chosen cross-sectional profiles are defined in Fig. 2 and Table 2, respectively. To minimize the Local 


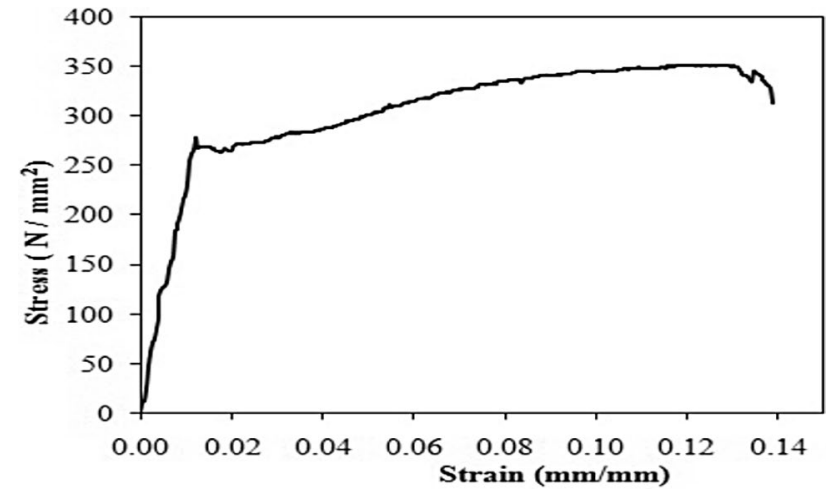

Fig. 1 Stress-strain curve

Table 1 Average result coupon test

\begin{tabular}{llll}
\hline $\begin{array}{l}\text { Yield stress } \\
(\mathrm{Mpa})\end{array}$ & $\begin{array}{l}\text { Young's modulus } \\
(\mathrm{Mpa})\end{array}$ & $\begin{array}{l}\text { Ultimate stress } \\
(\mathrm{Mpa})\end{array}$ & Elongation \\
\hline 272 & $2.05 \times 10^{5}$ & 351 & $13 \%$ \\
\hline
\end{tabular}

Buckling (LB), all the cross-sectional dimensions are selected based on the AISI S 100-2007 (2007) and the pre-qualified section dimensions are given in the DSM. The specimens are fabricated by the press-braking operation. All the sections are tested under simply supported end condition subjected to two-point loading. A loading frame of a capacity of $250 \mathrm{kN}$ is used to test the specimen and load is applied using a hydraulic jack. The applied load and displacements are measured using proving ring and dial gauges, respectively. The specimens are laterally restrained at the support. Each test is started with a preload sequence of approximately $5 \mathrm{kN}$ is given to the specimen. In this way, the possible tolerances at the supports are minimized. The experimental setup and instrumentation are detailed in Fig. 3.

\section{Details of the finite element model}

The parts of the built-up section are arranged by an assembly option in the ABAQUS. Finite Element Model (FEM) is based on the centerline dimension of the cross section. The geometry is simulated using shell element S4R, of which the element size is chosen after a mesh refinement study. The finite element mesh size of $10 \times 10 \mathrm{~mm}$ is used. Residual stress and cold-forming process are ignored in developed FEM (Young and Ren 2006). Moreover, the built-up section is modelled using the fastener constraint pair option in the ABAQUS. The FEM is employed for both geometry and material nonlinear effects. A bilinear stress-strain curve is adopted for defining the material properties (Manikandan and Sukumar 2016a; Kankanamge and Mahendran 2010). Initial imperfection is incorporated in observance with the fundamental buckling mode shape attaining maximum amplitude of L/1000 (Xu et al. 2009). All the beams are analysed under simply supported end condition with two-point loading. To minimize the lateral movement at the support, the lateral constraint is provided (Manikandan and Sukumar 2015). A typical FEM is shown in Fig. 4.
Fig. 2 Cross-sectional geometries

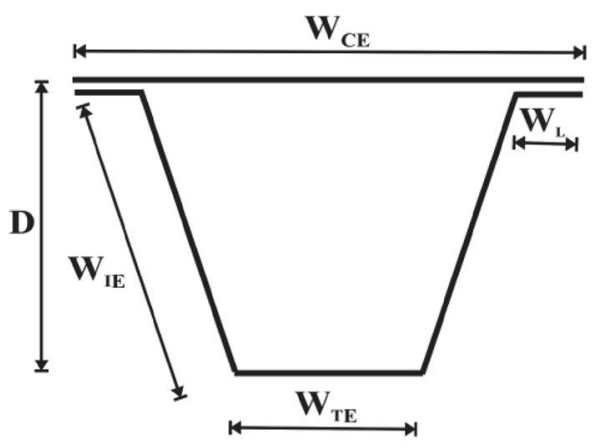

a HSS

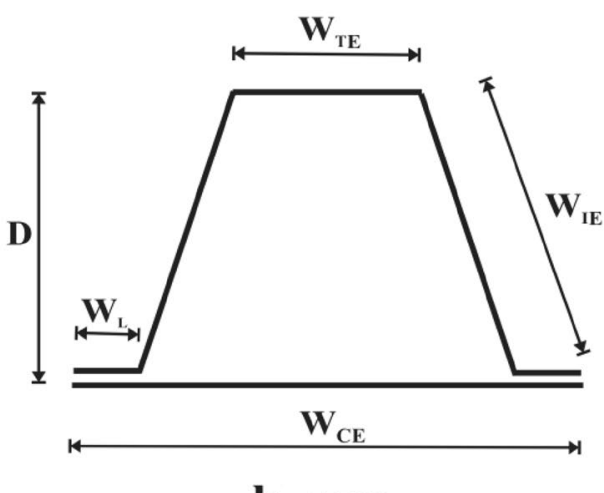

b IHSS
Table 2 Dimensions of the cross-sectional geometries

\begin{tabular}{lllllllll}
\hline S. no. & Specimen ID & \multicolumn{6}{l}{ Dimension of the section $(\mathrm{mm})$} \\
\cline { 3 - 8 } & & $W_{\mathrm{CE}}$ & $W_{\mathrm{TE}}$ & $W_{\mathrm{IE}}$ & $D$ & $W_{\mathrm{L}}$ & $t$ & $L$ \\
\hline 1 & HSS & 150 & 60 & 90 & 94 & 20 & 1.6 & 1200 \\
2 & IHSS & 150 & 60 & 90 & 94 & 20 & 1.6 & 1200 \\
\hline
\end{tabular}




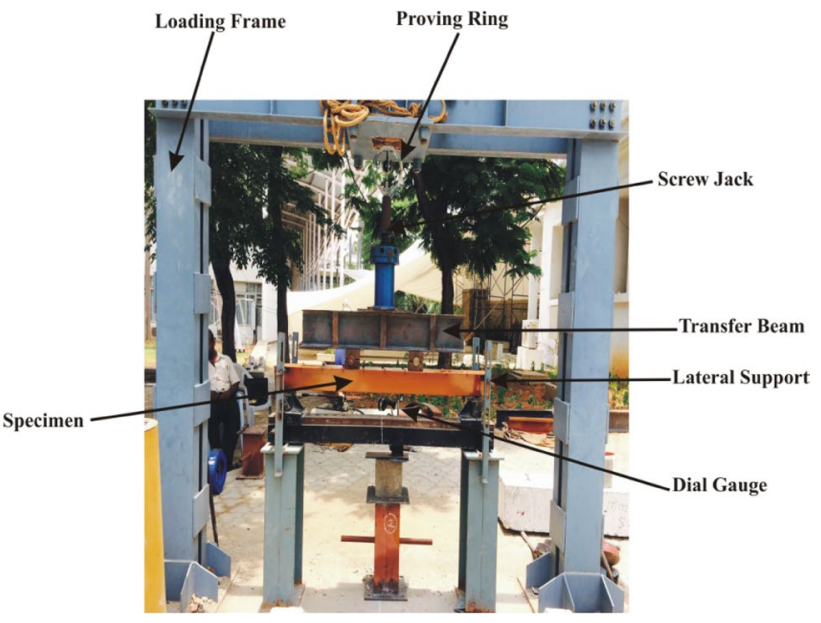

Fig. 3 Experimental setup

\section{Results and discussion}

All the tested sections have an equal cross-sectional area and equal length. Comparison between the test and FEM of the load-deflection curve and behaviour of the specimen is shown in Figs. 5, 6 and 7. Two types of specimens are tested. The first is normal Hat Shape Section (HSS) and the second is Inverted Hat Shape Section (IHSS). The flexural strength of HSS and IHSS is $3.96 \mathrm{kN} \mathrm{m}$ and $3.20 \mathrm{kN} \mathrm{m}$, respectively, in which HSS shown in Fig. 6 is failed by LB whereas IHSS in Fig. 7 is failed by the interaction of LB and Flexural Buckling (FB). From this study, it is observed that the specimen that has a large width-to-thickness ratio fails by LB, whereas the specimen that has a small width-to-thickness ratio fails by the interaction of LB and FB. After LB, the stresses on the compression element are redistributed across the width of the compression element until stresses reached the maximum.

The width-to-thickness ratio of the compression flange significantly affects the failure mode of the specimen. Table 3 shows the result of comparison between experiment $\left(P_{\mathrm{EXP}}\right)$ and numerical analysis $\left(P_{\mathrm{FEM}}\right)$. From the results, it is observed that numerical analysis accurately predicts the test results.

\section{Parametric study}

In the parametric study, the effect of length, depth, thickness and angle variation of the proposed section geometries are examined. Totally, 28 sections are analysed. The width of compression element, the width of tension element, the width of the inclined element, depth, size of the lip, thickness, length of the member and the angle of the inclined element are $150 \mathrm{~mm}, 60 \mathrm{~mm}, 94 \mathrm{~mm}, 90 \mathrm{~mm}$, $1.6 \mathrm{~mm}, 1200 \mathrm{~mm}$ and $75^{\circ}$, respectively. A type of cross

Fig. 4 Details of finite element model

Fig. 5 Load-deflection curve for specimen HSS and IHSS
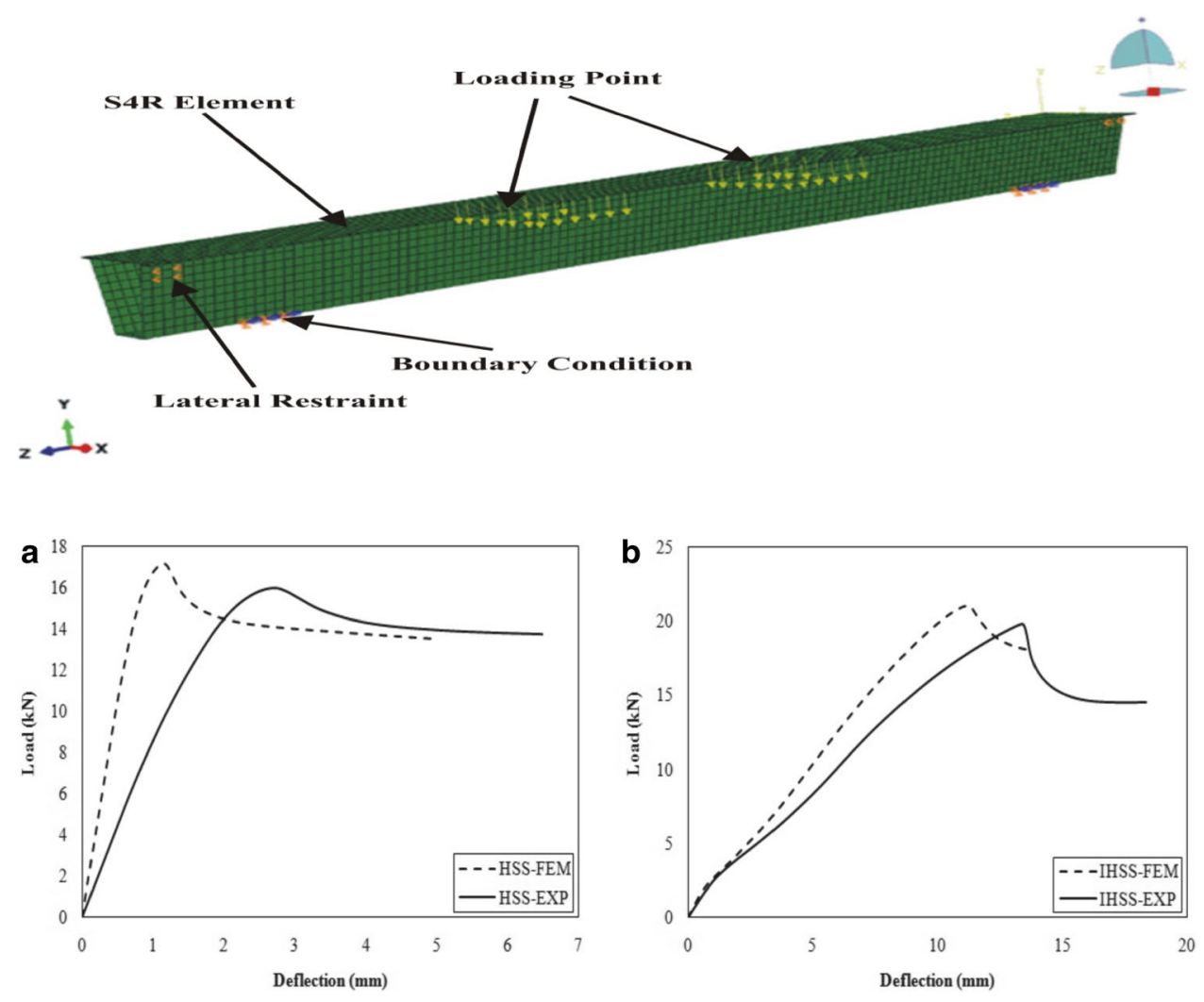

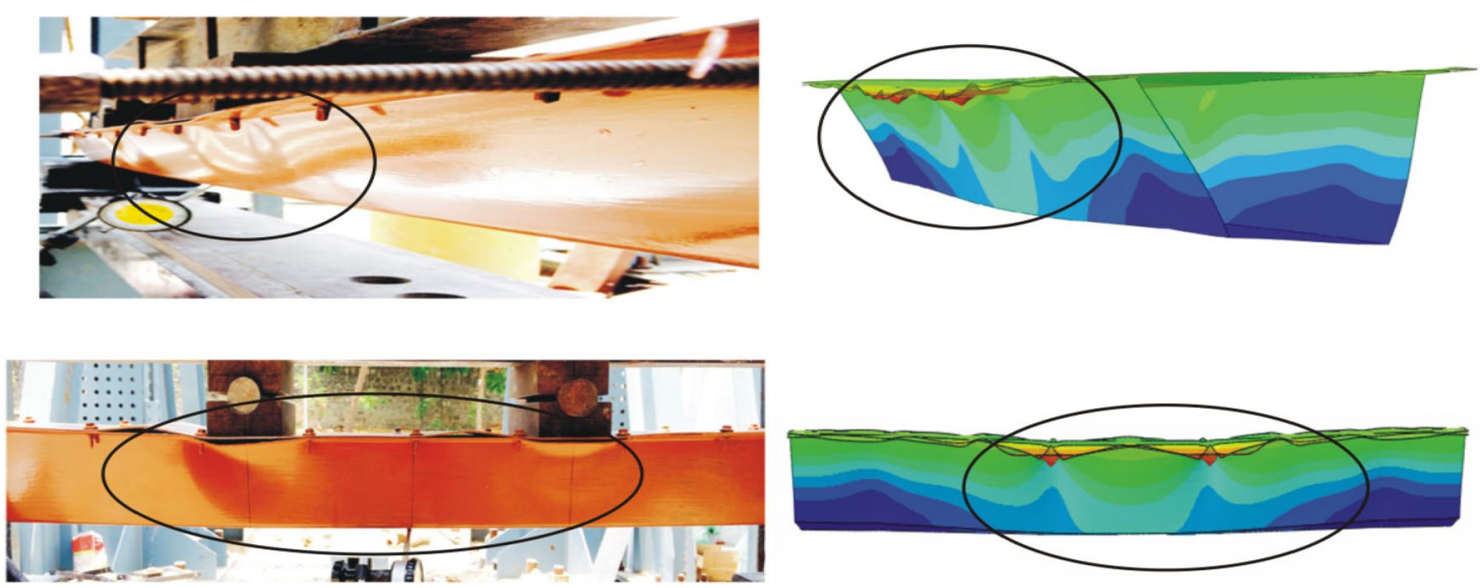

Fig. 6 Failure mode of specimen HSS

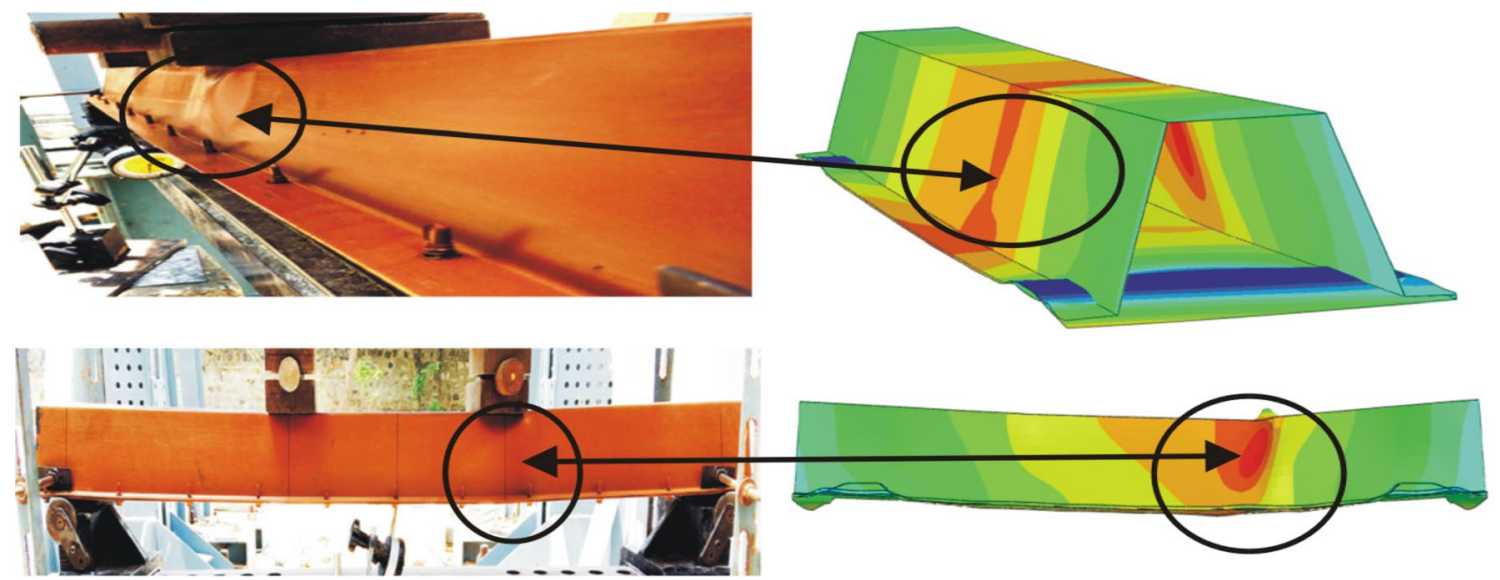

Fig. 7 Failure mode of specimen IHSS

Table 3 Comparison of results between experiment and finite element method

\begin{tabular}{lllll}
\hline Specimen ID & \multicolumn{2}{l}{$\begin{array}{l}\text { Flexural strength } \\
(\mathrm{kN} \mathrm{m})\end{array}$} & $P_{\text {EXP }}$ & Failure mode \\
\cline { 2 - 3 } & $P_{\text {EXP }}$ & $P_{\text {FEM }}$ & & $P_{\text {FEM }}$ \\
\hline HSS & 3.96 & 4.20 & 0.94 & $L$ \\
IHSS & 3.20 & 3.42 & 0.93 & $L+F$ \\
\hline
\end{tabular}

$L$ local buckling, $F$ flexural buckling

section and the corresponding variables are identified from the specimen labelling. As an example in "HSS-L800", the first letter defines the type of cross section (HSS-hat shape section) and the second letter defines the size of variables in $\mathrm{mm}$ (L800-length of the member, D80depth of the member, T1.6-thickness of the section and A75-angle of the element in degree).

\section{Effect of length variation}

To study the effect of length variation of the selected cross-sectional geometries, except the length all the section dimensions are kept constant and shown in Table 4. The length of the section is varied from 800 to $2400 \mathrm{~mm}$ with an increment of $400 \mathrm{~mm}$. These dimensional variations give the ten cross-sectional geometries. All the specimens are failed by the interaction of $\mathrm{LB}$ and $\mathrm{FB}$, whereas specimen HSS-L800 fails by the LB. From Fig. 8a, it is observed that the load-carrying capacity of the section increases with the increase in the length of the section, and further, it is decreased with the increase in length. For example, the flexural strength of HSS-L800 and IHSSL800 is $1.82 \mathrm{kN} \mathrm{m}$ and $2.62 \mathrm{kN} \mathrm{m}$, respectively. IHSS produces much strength compared to IHSS. The variation of flexural strength of HSS section is $43 \%$. From this study, it is concluded that the length variation of the HSS significantly affects the strength. 
Table 4 Results of parametric study

\begin{tabular}{|c|c|c|c|c|c|c|c|c|c|c|c|c|}
\hline \multirow[t]{2}{*}{ Specimen ID } & \multicolumn{7}{|c|}{ Dimension of the section (mm) } & \multirow[t]{2}{*}{$\theta$} & \multicolumn{2}{|c|}{$\begin{array}{l}\text { Flexural } \\
\text { strength } \\
(\mathrm{kN} \mathrm{m})\end{array}$} & \multirow{2}{*}{$\begin{array}{c}M_{\mathrm{FEA}} \\
M_{\mathrm{DSM}}\end{array}$} & \multirow[t]{2}{*}{ Failure mode } \\
\hline & $W_{\mathrm{CE}}$ & $W_{\mathrm{TE}}$ & $W_{\mathrm{IE}}$ & $D$ & $W_{\mathrm{L}}$ & $t$ & $L$ & & $M_{\mathrm{FEA}}$ & $M_{\mathrm{DSM}}$ & & \\
\hline HSS-L800 & 150 & 60 & 94 & 90 & 20 & 1.6 & 800 & 75 & 1.82 & 2.11 & 0.86 & $L$ \\
\hline HSS-L1200 & 150 & 60 & 94 & 90 & 20 & 1.6 & 1200 & 75 & 3.28 & 4.07 & 0.81 & $L+F$ \\
\hline HSS-L1600 & 150 & 60 & 94 & 90 & 20 & 1.6 & 1600 & 75 & 3.32 & 4.25 & 0.78 & $L+F$ \\
\hline HSS-L2000 & 150 & 60 & 94 & 90 & 20 & 1.6 & 2000 & 75 & 3.59 & 4.48 & 0.80 & $L+F$ \\
\hline HSS-L2400 & 150 & 60 & 94 & 90 & 20 & 1.6 & 2400 & 75 & 3.45 & 4.25 & 0.81 & $L+F$ \\
\hline IHSS-L800 & 150 & 60 & 94 & 90 & 20 & 1.6 & 800 & 75 & 2.62 & 3.19 & 0.82 & $L$ \\
\hline IHSS-L1200 & 150 & 60 & 94 & 90 & 20 & 1.6 & 1200 & 75 & 4.20 & 5.31 & 0.79 & $L+F$ \\
\hline IHSS-L1600 & 150 & 60 & 94 & 90 & 20 & 1.6 & 1600 & 75 & 4.66 & 5.78 & 0.81 & $L+F$ \\
\hline IHSS-L2000 & 150 & 60 & 94 & 90 & 20 & 1.6 & 2000 & 75 & 4.99 & 6.28 & 0.80 & $L+F$ \\
\hline IHSS-L2400 & 150 & 60 & 94 & 90 & 20 & 1.6 & 2400 & 75 & 4.86 & 6.02 & 0.81 & $L+F$ \\
\hline HSS-D80 & 150 & 67 & 84 & 80 & 20 & 1.6 & 1200 & 75 & 3.12 & 3.50 & 0.89 & $L+F$ \\
\hline HSS-D90 & 150 & 60 & 94 & 90 & 20 & 1.6 & 1200 & 75 & 3.28 & 3.60 & 0.91 & $L+F$ \\
\hline HSS-D100 & 150 & 56 & 104 & 100 & 20 & 1.6 & 1200 & 75 & 3.92 & 4.31 & 0.91 & $L+F$ \\
\hline HSS-D110 & 150 & 50 & 114 & 110 & 20 & 1.6 & 1200 & 75 & 4.37 & 4.90 & 0.89 & $L+F$ \\
\hline IHSS-D80 & 150 & 67 & 84 & 80 & 20 & 1.6 & 1200 & 75 & 3.42 & 3.67 & 0.93 & $L+F$ \\
\hline IHSS-D90 & 150 & 60 & 94 & 90 & 20 & 1.6 & 1200 & 75 & 4.20 & 4.79 & 0.88 & $L+F$ \\
\hline IHSS-D100 & 150 & 56 & 104 & 100 & 20 & 1.6 & 1200 & 75 & 4.88 & 5.02 & 0.97 & $L+F$ \\
\hline IHSS-D110 & 150 & 50 & 114 & 110 & 20 & 1.6 & 1200 & 75 & 5.38 & 6.31 & 0.85 & $L+F$ \\
\hline HSS-T1.6 & 150 & 60 & 94 & 90 & 20 & 1.6 & 1200 & 75 & 3.28 & 3.60 & 0.91 & $L+F$ \\
\hline HSS-T2 & 150 & 60 & 94 & 90 & 20 & 2 & 1200 & 75 & 4.83 & 5.02 & 0.96 & $L+F$ \\
\hline HSS-T3 & 150 & 60 & 94 & 90 & 20 & 3 & 1200 & 75 & 8.90 & 9.56 & 0.93 & $F$ \\
\hline IHSS-T1.6 & 150 & 60 & 94 & 90 & 20 & 1.6 & 1200 & 75 & 4.20 & 4.98 & 0.84 & $L+F$ \\
\hline IHSS-T2 & 150 & 60 & 94 & 90 & 20 & 2 & 1200 & 75 & 4.89 & 5.23 & 0.94 & $L+F$ \\
\hline IHSS-T3 & 150 & 60 & 94 & 90 & 20 & 3 & 1200 & 75 & 9.00 & 10.01 & 0.90 & $F$ \\
\hline HSS-A75 & 150 & 60 & 94 & 90 & 20 & 1.6 & 1200 & 75 & 3.28 & 4.39 & 0.75 & $L+F$ \\
\hline HSS-A80 & 150 & 60 & 94 & 90 & 20 & 1.6 & 1200 & 80 & 3.70 & 4.60 & 0.80 & $L+F$ \\
\hline IHSS-A75 & 150 & 60 & 94 & 90 & 20 & 1.6 & 1200 & 75 & 4.20 & 4.80 & 0.88 & $L+F$ \\
\hline IHSS-A80 & 150 & 60 & 94 & 90 & 20 & 1.6 & 1200 & 80 & 3.99 & 4.56 & 0.87 & $L+F$ \\
\hline Mean & & & & & & & & & & & 0.86 & \\
\hline Standard devi & tion & & & & & & & & & & 0.06 & \\
\hline
\end{tabular}

$L$ local buckling, $F$ local and flexural buckling

\section{Effect of depth variation}

To study the effect of depth variation of the selected crosssectional geometries, except the depth, all the section dimensions are kept constant as shown in Table 4. The width of the inclined element $\left(W_{\mathrm{IE}}\right)$ is varied from $67 \mathrm{~mm}$, $60 \mathrm{~mm}, 56 \mathrm{~mm}$ to $50 \mathrm{~mm}$ and width of a tension element $\left(W_{\mathrm{TE}}\right)$ is varied from $84 \mathrm{~mm}, 94 \mathrm{~mm}, 104 \mathrm{~mm}$ to $114 \mathrm{~mm}$. Similarly, the depth of the section is varied from $80 \mathrm{~mm}$, $90 \mathrm{~mm}, 100 \mathrm{~mm}$ to $110 \mathrm{~mm}$, and all the other dimensions are constant. The effect of depth variations is presented in Table 4. From Fig. 8a, it is observed that the load-carrying capacity of the section increases with an increase in the depth of the section and a similar pattern of failure is observed in all the other specimens. When compared with HSS, the IHSS produces more strength.

\section{Effect of thickness variation}

To study the effect of thickness variation, thicknesses of the section are selected as $1.60 \mathrm{~mm}, 2.00 \mathrm{~mm}$ and $3.00 \mathrm{~mm}$. Effect of thickness variation of the specimens and magnitude of flexural strength as presented in Fig. 8c and Table 4, respectively. From this study, it is observed that the strength of the section increases with increasing the thickness of the section. 

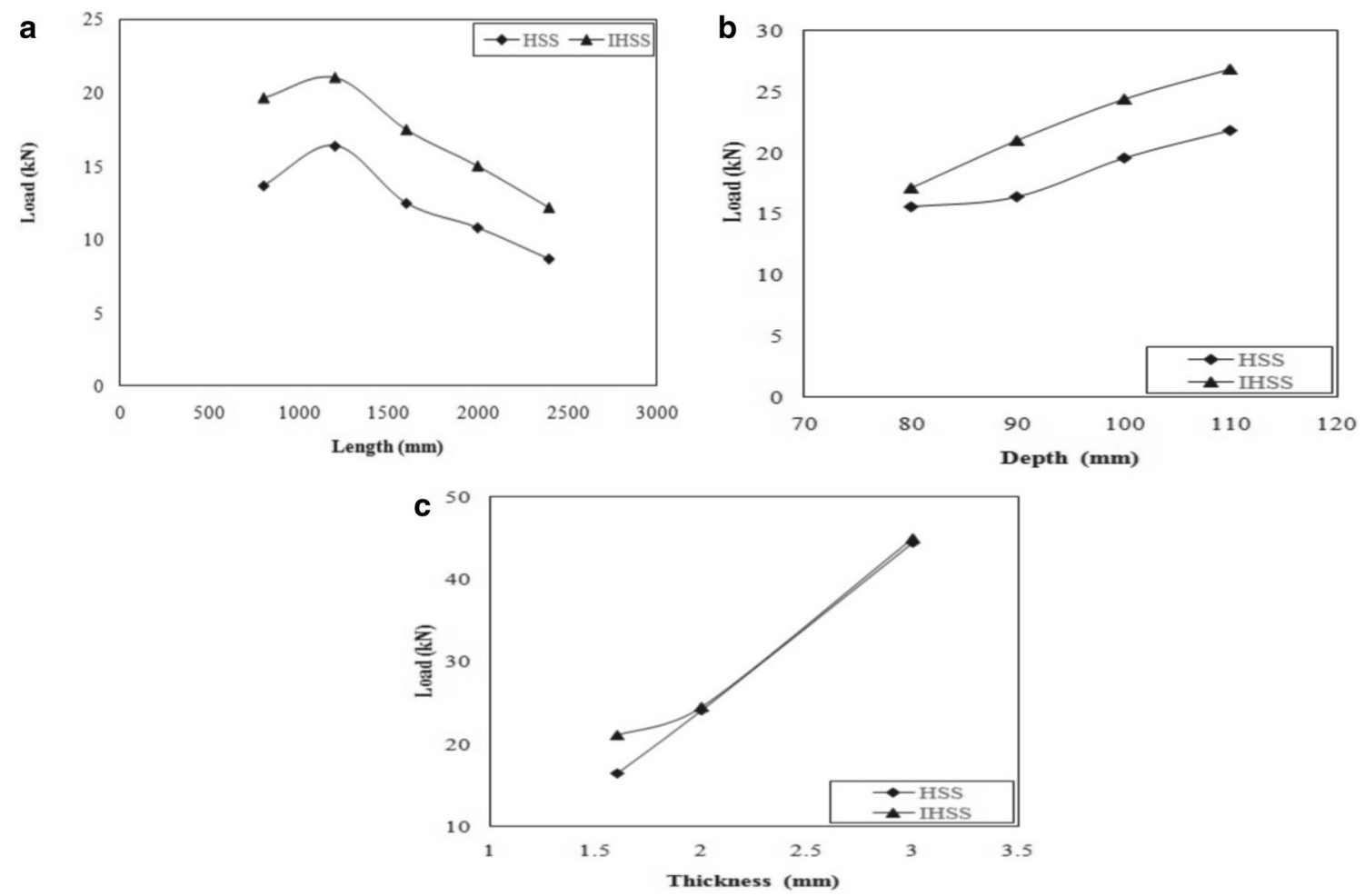

Fig. 8 Effect of variations of a length, $\mathbf{b}$ depth, $\mathbf{c}$ thickness

\section{Effect of angle variation}

To study the effect of angle variation of the selected crosssectional geometries, the angle of the element is varied from $60^{\circ}, 75^{\circ}$ to $80^{\circ}$. The effect of the angle of the inclined element is presented in Table 4. From this study, it is found that the strength of the section increases with the increasing angle of the inclined element. It is also observed that the length of the member, the depth of the sections and the angle of the inclined element significantly affect the strength and the behaviour of the section, whereas the thickness of the section does not significantly affect the behaviour of the section.

\section{Theoretical investigation}

As per the DSM specification for CFS, the nominal flexural strength $\left(M_{\mathrm{n}}\right)$ is the minimum of lateral-torsional buckling $\left(M_{\mathrm{ne}}\right)$, local buckling $\left(M_{\mathrm{nl}}\right)$ and distortional buckling $\left(M_{\mathrm{nd}}\right)$ as given below.

\section{Lateral-torsional buckling}

The nominal flexural strength, $M_{\mathrm{ne}}$, for lateral-torsional buckling is

for $M_{\text {cre }}<0.56 M_{y} M_{\text {ne }}=M_{\text {cre }}$, for $2.78 M_{y} \geq M_{\text {cre }} \geq 0.56 M_{y} \quad M_{\text {ne }}=\frac{10}{9} M_{y}\left(1-\frac{10 M_{y}}{36 M_{\text {cre }}}\right)$,

for $M_{\text {cre }}>2.78 M_{y} M_{\mathrm{ne}}=M_{y}$,

where $M_{y}=S_{g} F_{y}$, where $S_{g}$ is referenced to the extreme fibre in first yield and $M_{\text {cre }}$ is the critical elastic lateral-torsional buckling moment.

\section{Local buckling}

The nominal flexural strength, $M_{\mathrm{nl}}$, for local buckling is

for $\lambda_{1} \leq 0.776 \quad M_{\mathrm{nl}}=M_{\mathrm{ne}}$,

for $\lambda_{l}>0.776 \quad M_{\mathrm{nl}}=\left(1-0.15\left(\frac{M_{\mathrm{crl}}}{M_{\mathrm{ne}}}\right)^{0.4}\right)\left(\frac{M_{\mathrm{crl}}}{M_{\mathrm{ne}}}\right)^{0.4} M_{\mathrm{ne}}$,

where $\lambda_{1}=\sqrt{M_{\mathrm{ne}} / M_{\mathrm{crl}}}$ and $M_{\mathrm{crl}}$ is the critical elastic local buckling moment.

\section{Distortional buckling}

The nominal flexural strength, $M_{\text {nd }}$, for distortional buckling is for $\lambda_{\mathrm{d}} \leq 0.673 M_{\mathrm{nd}}=M_{y}$, 


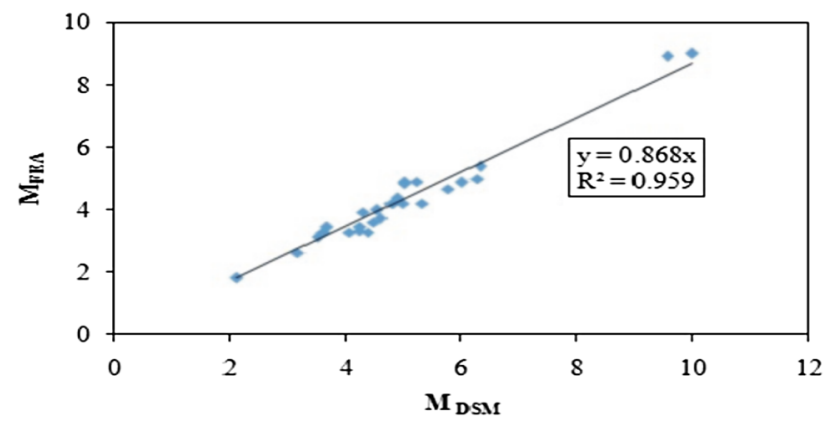

Fig. 9 Variations of $M_{\mathrm{DSM}}$ and $M_{\mathrm{FEA}}$

Table 5 Evaluation of design equation

\begin{tabular}{lcrrl}
\hline $\begin{array}{l}\text { Specimen ID as per } \\
\text { the literature }\end{array}$ & \multicolumn{3}{c}{ Flexural strength $(\mathrm{kN} \mathrm{m})$} & $M_{\text {EXP }}$ \\
\cline { 2 - 4 } & $M_{\text {EXP }}$ & \multicolumn{1}{c}{$M_{\text {DSM }}$} & $M_{\text {Design }}$ & $M_{\text {Design }}$ \\
\hline B1 & 6.64 & 6.99 & 6.07 & 0.91 \\
B3 & 7.48 & 8.01 & 6.95 & 0.93 \\
B5 & 12.8 & 13.44 & 11.67 & 0.91 \\
B6 & 9.39 & 9.55 & 8.29 & 0.88 \\
B8 & 8.94 & 9.86 & 8.56 & 0.96 \\
B9 & 7.08 & 7.76 & 6.74 & 0.95 \\
Mean & & & & 0.92 \\
Standard deviation & & & & 0.03 \\
\hline
\end{tabular}

for $\lambda_{\mathrm{d}}>0.776 M_{\mathrm{nl}}=\left(1-0.22\left(\frac{M_{\mathrm{crd}}}{M_{y}}\right)^{0.5}\right)\left(\frac{M_{\mathrm{crd}}}{M_{y}}\right)^{0.5} M_{y}$,

where $\lambda_{\mathrm{d}}=\sqrt{M_{y} / M_{\mathrm{crd}}}$, and $M_{\text {crd }}$ is the critical elastic distortional buckling moment.

All the results of the parametric studies are compared with the DSM specification, and the comparison between $M_{\mathrm{DSM}}$ and $M_{\mathrm{FEA}}$ is shown in Table 4 . The corresponding mean and standard deviation between $M_{\mathrm{DSM}}$ and $M_{\mathrm{FEA}}$ are 0.86 and 0.06 , respectively. The comparison shows that the ratio between $M_{\mathrm{DSM}}$ and $M_{\mathrm{FEA}}$ is less than one. All the specimens fail by interactive failure mode. From the results of this study, it is concluded that the DSM specification provides unconservative results. Hence, to estimate the accurate result of built-up closed hat section, a linear regression analysis is made between $M_{\mathrm{DSM}}$ and $M_{\text {FEA }}$ as shown in Fig. 9. The relationship between $M_{\mathrm{DSM}}$ and $M_{\mathrm{FEA}}$ is $M_{\mathrm{FEA}}=0.868 M_{\mathrm{DSM}}$ with a regression coefficient of 0.959 . The design equation is evaluated with the results available from the literature (Manikandan and Sukumar 2016) and the comparisons are presented in Table 5. Similarly, the corresponding mean deviation of $M_{\text {EXP }}$ and $M_{\text {Design }}$ is 0.92 and $0.0,3$ respectively. From the results, it is concluded that the design equation exactly predicts the flexural strength of CFS built-up closed hat section under bending.

\section{Summary and conclusion}

A two series of different cross-sectional geometries, hat shape section and inverted hat shape section, are chosen. Numerical analysis is carried out using ABAQUS. All selected specimens are tested under pinned end condition subjected to two-point loading. The material properties are obtained from the coupon test. Material and geometric non-linearities are incorporated in the FEM. After validation, a total of 28 sections is analysed numerically. In this parametric study, the effect of length, depth, thickness and angle variation of the proposed section geometries is investigated using the verified FEM.

- The FE model developed is well suitable for parametric studies.

- Local and flexural buckling significantly affect the strength and the behaviour of the section.

- During the design of the built-up section, consideration of interactive buckling is required.

- No local buckling occurs in specimens with the small width-to-thickness ratio.

- The failure mode of the specimen varies with the width-to-thickness ratio of the compression flange.

- Local buckling significantly reduces the strength of the section.

- Load-carrying capacity of the section increases with the increase in the length of the section, and further, it is decreasing with the increase in length.

- In the hat-shaped section, when compared with normal hat-shaped section, the inverted hat-shaped section produces more strength.

- From this study, it is observed that the length of the member, the depth of the sections and the angle of the inclined element significantly affect the strength and the behaviour of the section, whereas the thickness of the section does not significantly affect the behaviour of the section.

The design equation developed is valid for the CFS built-up closed hat section under bending.

Open Access This article is distributed under the terms of the Creative Commons Attribution 4.0 International License (http://creativeco mmons.org/licenses/by/4.0/), which permits unrestricted use, distribution, and reproduction in any medium, provided you give appropriate credit to the original author(s) and the source, provide a link to the Creative Commons license, and indicate if changes were made. 


\section{References}

AISI S 100-2007 (2007) Specification for the design of cold-formed steel structural members, 2007th edn. American Iron and steel Institute, Washington

Alex J, Iyappan GR (2016) Experimental study on flexural behaviour of cold formed steel section. Int J Innov Res Sci Eng Technol 40:219-222

Beshara B, Lawson TJ (2002) Built-up girder screw connection variation flexural tests. Dietrich Design Group Internal Report

Haidarali MR, Nethercot DA (2012a) Local and distortional buckling of cold-formed steel beams with edge-stiffened flanges. J Constr Steel Res 54:106-111

Haidarali MR, Nethercot DA (2012b) Local and distortional buckling of cold-formed steel beams with both edge and intermediate stiffeners in their compression flanges. Thin Walled Struct 73:37-42

IS: 1608-2006, Indian specification FOR mechanical testing of materials-tensile testing, India

Kankanamge ND, Mahendran M (2010) Behaviour and design of coldformed steel beams subject to lateral-torsional buckling. Thin Walled Struct 51:25-38

Ma JL, Chan T, Young B (2016) Experimental investigation of coldformed high strength steel tubular beams. Eng Struct 126:200-209

Manikandan P, Sukumar S (2015) Behaviour of stiffened cold-formed steel built-up sections with complex edge stiffeners under bending. KSCE J Civ Eng 19(7):2108-2115

Manikandan P, Sukumar S (2016a) Flexural behaviour of cold-formed steel built-up closed sections with intermediate web stiffeners under bending. Asian J Civ Eng 17(2):249-257
Manikandan P, Sukumar S (2016b) Effect of stiffened element and edge stiffener in strength and behaviour of cold formed steel built-up beams. J Adv Comput Design An Int J 1(2):207-220

Manikandan P, Sukumar S, Naresh LS (2012) Finite element modelling of cold-formed beams with intermediate stiffeners. Int J Earth Sci Eng 5:547-553

Manikandan P, Sukumar S, Balaji TU (2014) Effective shaping of coldformed thin-walled built-up beams in pure bending. Arab J Sci Eng 39:6043-6054

Pan CL, Yu WW (2002) Bending strength of hybrid cold-formed steel beams. Thin Walled Struct 40:399-414

Serrette RL (2004) Performance of edge-loaded cold formed steel builtup box beams. J Struct Eng 3(9):170-174

Sonu JK, Singh KD (2017) Shear behaviour of single perforated lean duplex stainless steel (LDSS) rectangular hollow beams. Thin Walled Struct 119:851-867

Xu L, Sultana P, Zhou X (2009) Flexural strength of cold-formed steel built-up sections. Thin Walled Struct 47:807-815

Young B, Ren W (2006) Finite-element simulation and design of coldformed steel channels subjected to web crippling. J Struct Eng 132(12):1967-1974

Publisher's Note Springer Nature remains neutral with regard to jurisdictional claims in published maps and institutional affiliations. 